\title{
Neural stem cell-like cells derived from autologous bone mesenchymal stem cells for the treatment of patients with cerebral palsy
}

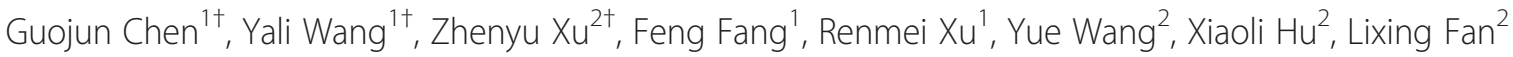
and Houqi Liu ${ }^{2 *}$

\begin{abstract}
Background: Stem cell therapy is a promising treatment for cerebral palsy, which refers to a category of brain diseases that are associated with chronic motor disability in children. Autologous MSCs may be a better cell source and have been studied for the treatment of cerebral palsy because of their functions in tissue repair and the regulation of immunological processes.

Methods: To assess neural stem cell-like (NSC-like) cells derived from autologous marrow mesenchymal stem cells as a novel treatment for patients with moderate-to-severe cerebral palsy, a total of 60 cerebral palsy patients were enrolled in this open-label, non-randomised, observer-blinded controlled clinical study with a 6-months follow-up. For the transplantation group, a total of 30 cerebral palsy patients received an autologous NSC-like cells transplantation (1-2 $\times 10^{7}$ cells into the subarachnoid cavity) and rehabilitation treatments whereas 30 patients in the control group only received rehabilitation treatment.

Results: We recorded the gross motor function measurement scores, language quotients, and adverse events up to 6 months post-treatment. The gross motor function measurement scores in the transplantation group were significantly higher at month 3 (the score increase was 42.6, 95\% Cl: 9.8-75.3, $P=.011$ ) and month 6 (the score increase was 58.6, 95\% Cl: 25.8-91.4, $P=.001$ ) post-treatment compared with the baseline scores. The increase in the Gross Motor Function Measurement scores in the control group was not significant. The increases in the language quotients at months 1, 3, and 6 post-treatment were not statistically significant when compared with the baseline quotients in both groups. All the 60 patients survived, and none of the patients experienced serious adverse events or complications.
\end{abstract}

Conclusion: Our results indicated that NSC-like cells are safe and effective for the treatment of motor deficits related to cerebral palsy. Further randomised clinical trials are necessary to establish the efficacy of this procedure.

Keywords: Cerebral palsy, Neural stem cell-like cells, Bone marrow mesenchymal stem cells, Cell therapy, Autologous transplantation

\footnotetext{
* Correspondence: houqiliu@126.com

${ }^{\dagger}$ Equal contributors

${ }^{2}$ Research Center of Developmental Biology, Second Military Medical

University, 800 Xiangyin Road, Shanghai 200433, China

Full list of author information is available at the end of the article
} 


\section{Background}

Childhood cerebral palsy is a non-progressive brain disease that results from various cerebral insults that can occur before birth and 1 month after birth. Patients primarily present with motor developmental delay or motor dysfunction and possible mental retardation, epilepsy, behavioural disorders, and sensory and perceptual disturbances. Hypoxic ischemic encephalopathy and premature cerebral palsy are the most common causes of cerebral palsy [1,2]. A census conducted in six cities in 1998 revealed that the prevalence of cerebral palsy in children 1 to 6 years of age was $1.92 \%$ [3]. The incidence of cerebral palsy in preschoolers in the United States has ranged from 3\%-4\% [4]. Children with cerebral palsy may impart a heavy burden on their families and society. Conventional therapies for treating cerebral palsy include physical therapy, motor function training, language training, orthomorphia, neurotomy, and intramuscular injections of botulinum toxin A. However, these methods have not improved cerebral injuries in patients with moderate-to-severe cerebral palsy $[5,6]$.

Stem cell transplantation is a novel and promising treatment for cerebral palsy $[7,8]$. However, this procedure is still in the initial stages of investigation [9], and there have not been any published results from clinical trials to date [10]. Several types of stem cells are candidates for the treatment of cerebral palsy, such as human embryonic neural stem cells, olfactory ensheathing cells, umbilical mesenchymal stem cells, and bone marrow MSCs $[7,8,11,12]$. However, human embryonic neural stem cells and olfactory ensheathing cells are difficult to apply in clinical practice due to the potential immunological rejection of xenogenic cells, ethical arguments, a high risk of transplantation within the brain, and the difficulty of repeated transplantations [9]. Autologous MSCs may be a better cell source and have been studied for the treatment of cerebral palsy because of their functions in tissue repair and the regulation of immunological processes [13]. In addition, previous studies have demonstrated that human bone marrow MSCs exhibit neural phenotypes and can differentiate into NSC-like cells in vitro [14-16]. Moreover, intraspinal cell therapy has led to better outcomes for neurological disorders in animal-based studies $[17,18]$ and clinical trails $[19,20]$. Therefore, we hypothesized that an intraspinal infusion of autologous MSCs-derived NSC-like cells may be a novel treatment for patients with moderateto-severe cerebral palsy. In a controlled clinical study, we investigated the clinical outcomes of 30 cerebral palsy patients who underwent transplantation with NSC-like cells and who were followed up for 6 months.

\section{Methods}

\section{Study design and patient enrolment}

An open-label, non-randomised, observer-blinded controlled clinical study was conducted. The study was approved by the Ethics Committee and the Science Committee of the Armed Police General Hospital of Zhejiang Province, China and was registered in the China Clinical Trial Registry (ChiCTR-TRC-12002056). Informed consent was obtained from all of the patients or their parents. A total of 60 patients with cerebral palsy with Gross Motor Function Classification System (GMFCS, corresponding to GMFCS E\&R 2007) levels III-V were enrolled in this study from June 2010 to June 2011. Overall, 30 patients were treated with conventional methods and stem cell transplantation and were included in the transplantation group. An additional 30 patients with cerebral palsy were only treated with conventional methods and were included in the control group. The study protocol is shown in Figure 1.

The patients were enrolled according to the following inclusion criteria [3]: (1) the presence of non-progressive, neurological disorders that appeared in infancy or early childhood; (2) the appearance of retardation including the lack of development or ability in sporting activities and the persistence of posture obstacles, which may be associated with lesions that affect feeling, perception, cognition, communication, and behaviour, epilepsy or secondary musculoskeletal problems; (3) no diagnosis of other diseases, such as metabolic or degenerative diseases, that could induce central paralysis and transient retardation in a normal person; and (4) negative serological markers for AIDS, hepatitis, and syphilis. Patients with severe anaphylactic or autoimmune diseases were excluded from the transplantation group.

\section{Autologous MSC cultures}

Patients fasted for 4-6 hours and went without water 1 hour before the collection of autologous bone marrow specimens. The patients were injected with $5 \mathrm{mg} / \mathrm{kg}$ phenobarbital, $0.01 \mathrm{mg} / \mathrm{kg}$ atropine, and $4 \mathrm{mg} / \mathrm{kg}$ ketamine in the aseptic collecting room 30 minutes before specimen collection. In addition, 8-25 mL of bone marrow $(0.6-1.0 \mathrm{~mL} / \mathrm{kg}$ of body weight) was collected from the right posterior superior iliac spine according to conventional bone marrow aspiration procedures. A total of $100 \mathrm{U} / \mathrm{mL}$ heparin was added to the collecting tube as an anticoagulant. Following current manufacturing best practices, mononuclear bone marrow cells were isolated by Percoll $(1.073 \mathrm{~g} / \mathrm{mL})$ centrifugation and were allowed to adhere to a flask for 72 hours in low glucose Dulbecco's Modified Eagle's Medium (GibcoInvitrogen) at $5 \% \mathrm{CO}_{2}$ and $37^{\circ} \mathrm{C}$, and the media were changed every 3 days. The cells with a strong positive signal for the multipotential marker Oct 4 and Nanog were screened for further cloning and culturing (Additional file 1: Figure S1A). The cell phenotypes were assessed by flow cytometry. The results indicated that CD34 and CD45 were negative, and the positive rates of CD29 and CD44 were above 95\% (Additional file 1: Figure S1B). The ability of the cells to 


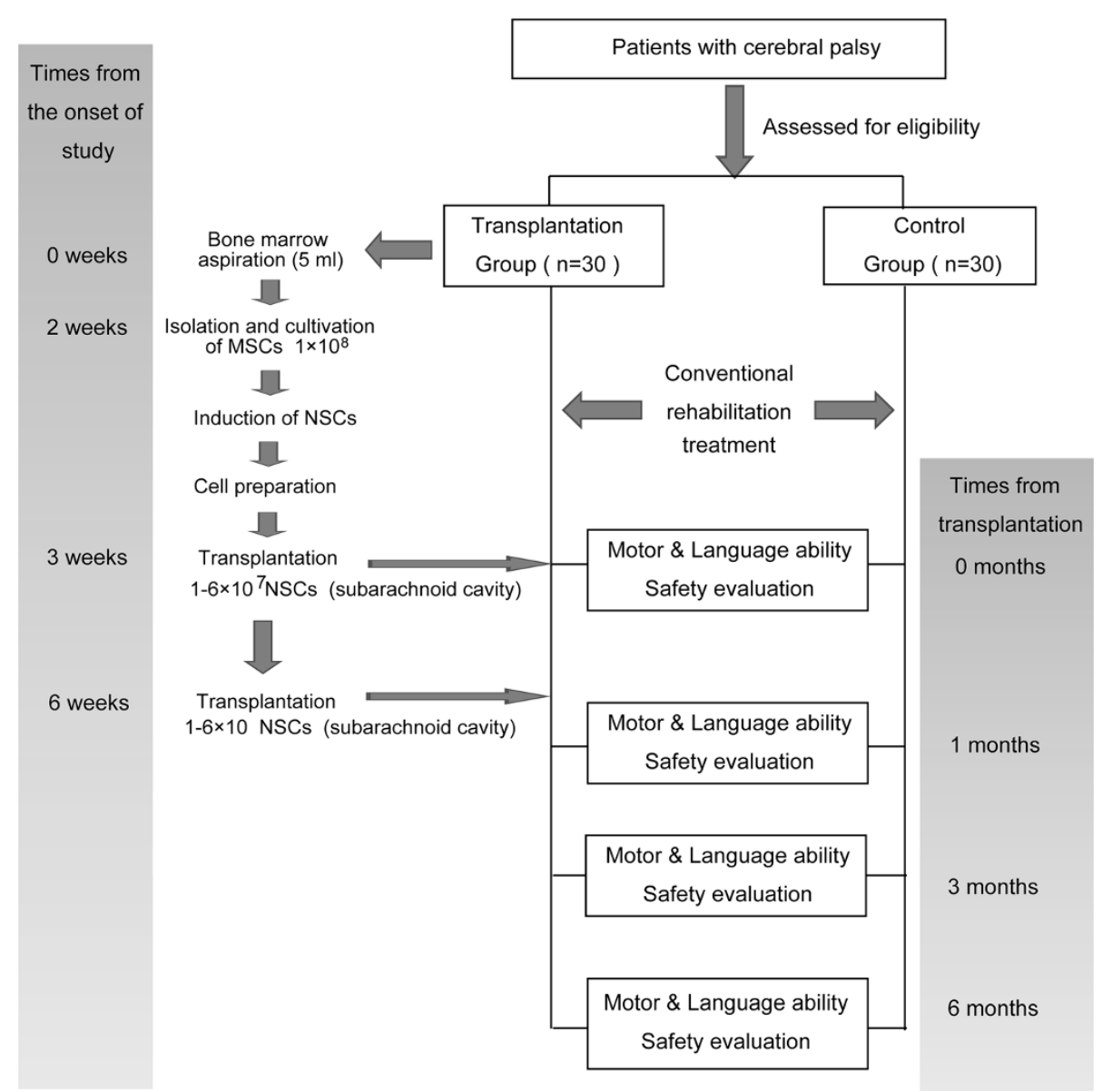

Figure 1 Study protocol. A total of 60 patients with cerebral palsy with Gross Motor Function Classification System (GMFCS) levels III-V were enrolled in this study. For the transplantation group, a total of 30 cerebral palsy patients received the autologous NSC-like cell transplantation and rehabilitation treatments whereas 30 patients in the control group only received rehabilitation treatment. The study protocol is shown. Motor ability was assessed using the Gross Motor Function Measure questionnaire-88. Language ability was measured using the Gesell questionnaire. All of the assessments were conducted by a specifically assigned person, and the assessment results were recorded in the case report. A safety evaluation was performed during the 6-month follow-up to detect instances of death, any serious clinical events, abnormal

electroencephalogram results, and neuroimaging complications.

differentiate into adipocytes and osteocytes in culture was confirmed in vitro following the criteria of the 2006 International Society of Cellular Therapy [21]. At 70\%-80\% confluence, the cells were detached and replated at $5 \times 10^{6} \%$ $175 \mathrm{~cm}^{2}$ in culture to process for neural differentiation and confirm negativity for endotoxin, hepatitis $C$ virus, hepatitis $\mathrm{B}$ virus, HIV, syphilis, fungus, Myco plasma species, and Chlamydia before infusion. A G-banding karyotype analysis was performed to confirm the absence of chromosomal aberrations in the final cellular product. The MSCs were continuously cultured without cryopreservation and were thawed before transplantation. Supplementary methods were shown in more detail (see Additional file 1).

\section{Autologous NSC-like cells induction and differentiation} At $30 \%-40 \%$ confluence, a combination of $20 \mathrm{ng} / \mathrm{ml} \mathrm{re-}$ combinant human FGF basic (bFGF) and $10 \mathrm{nM}$ retinoic acid was added to the medium for 12 hours to transform the MSCs, and the differentiation capacity was evaluated after 14 days [14]. Growth curves were drawn to assess the proliferation ability of the MSCs and the transformed cells (Figure $2 \mathrm{~A}$ ). In total, $1 \times 10^{4}$ of the transformed cells were collected to prepare slices for immunofluorescence staining, and $50 \%-70 \%$ of the cells expressed Nestin and Tuj-1 (Figure 2B). A total of $1 \times$ $10^{6}$ cells were co-labelled with antibodies against Nestin (BD Pharmingen) and Tuj-1 (Abcam), Sox2 (Abcam) or Sox1 (Santa Cruz). According to the flow cytometry analysis, $66.83 \%, 90.92 \%$ and $64.71 \%$ of the induced cells expressed both Nestin and Tuj-1, Sox 2 and Sox1, respectively (Figure 2B). These results suggest that the MSCs differentiated into NSC-like cells. The NSC-like cells were detached, washed three times in saline, resuspended in saline with 5\% human albumin and filtered 


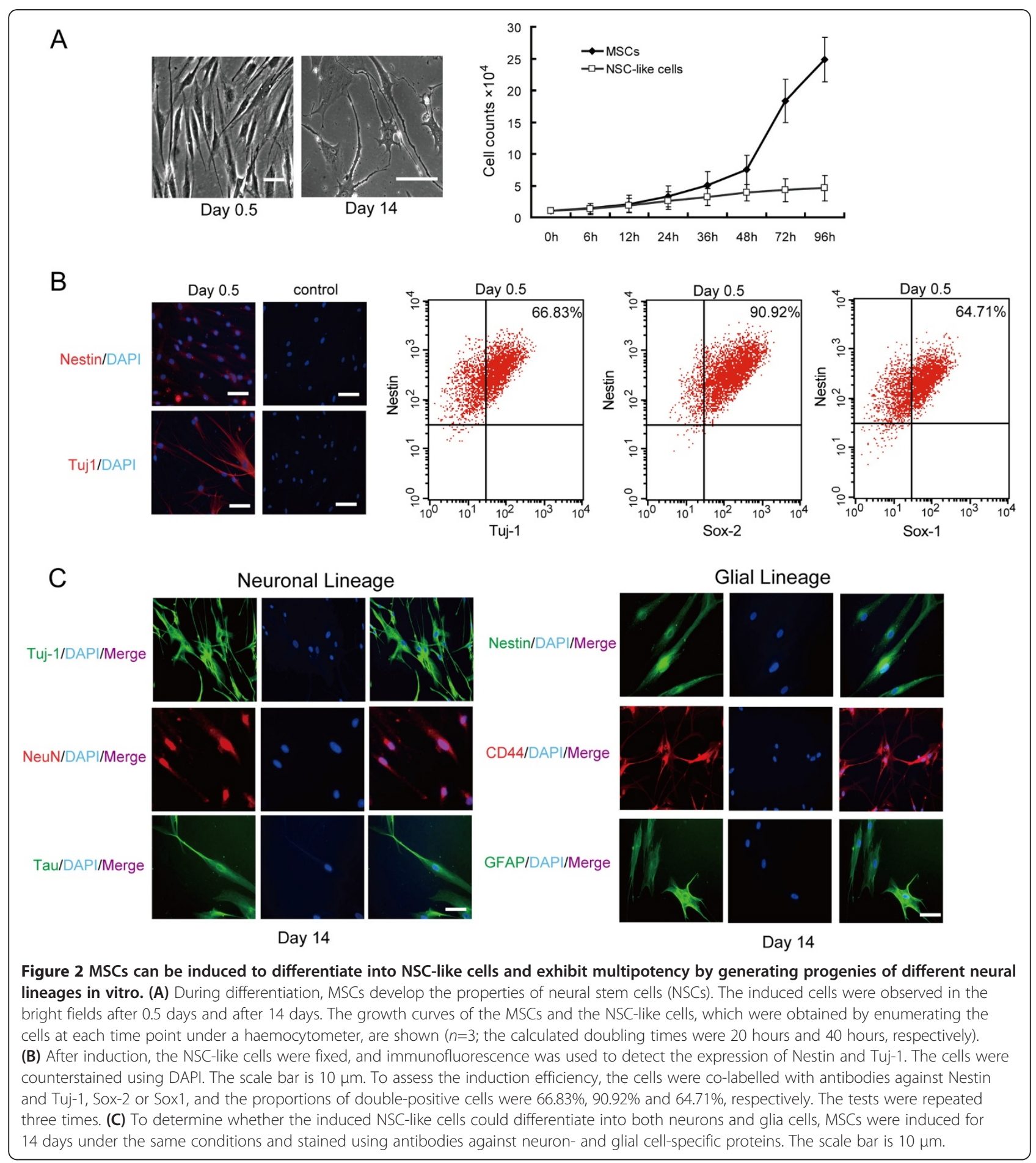

in a $100-\mu \mathrm{m}$ nylon filter. Approximately $100 \mu \mathrm{l}$ of this solution was used for safety and viability tests. No chromosomal aberrations or increased telomerase activity was found for the induced NSC-like cells. In addition, a high cell viability (>90\%) and the negative microbiological results ensured the quality of the cells before the transplantations. To determine whether the induced
NSC-like cells could differentiate into different neural lineages, MSCs were induced for 14 days under the same conditions and were stained using antibodies against Tuj-1 (Abcam), NeuN (Abcam), Tau (Abcam), Nestin (Santa Cruz), CD44 (Santa Cruz) and GFAP (Santa Cruz). The induced cells expressed both neuron- and glial cell-specific proteins (Figure 2C). 


\section{Safety evaluation of NSC-like cells in vivo in a mouse model}

The MSC-derived NSC-like cells $\left(1.0 \times 10^{6}\right)$ were implanted subcutaneously into the flanks of nude mice or were transplanted intraspinally into the subarachnoid space of nude mice. No tumour formation or other adverse events were observed in mice after 3 months. The animal studies were approved by the Institutional Animal Care and Use Committee of the Second Military Medical University in Shanghai, China.

\section{Cell transplantation therapy}

Before the lumbar puncture, the patients fasted without food and water. The patients were injected with phenobarbital sodium, atropine, and ketamine according to the dose and usage guidelines before the collection of bone marrow. When the patients fell asleep, a local anaesthetic was infiltrated under the skin and a spinal needle was inserted between the lumbar vertebrae L3/L4 or L4/ L5 and pushed in until the needle traversed the dura mater and the thin arachnoid membrane into the subarachnoid space. The stylet from the spinal needle was withdrawn, and drops of cerebrospinal fluid (up to $5 \mathrm{ml}$ ) were collected. Then, $5 \mathrm{ml}$ cell suspension, which contained 1-2 $\times 10^{7}$ of NSC-like cells, was gently injected into the subarachnoid cavity through the spinal needle. The opening pressure of the cerebrospinal fluid was measured during specimen collection using a simple column manometer. The procedure ended by withdrawing the needle while placing pressure on the puncture site. The cell transplantation was administered at intervals of 3 weeks for two cycles. In addition, the patients in the transplantation group received rehabilitation treatments at the same time.

\section{Observation indices}

As the primary measurement, the motor and language abilities of the patients were observed before treatment and at 1, 3, and 6 months post-treatment. Motor ability was assessed using the Gross Motor Function Measure (GMFM-88 or GMFM) [22] questionnaire. An example was shown in Additional file 1. Language ability was measured using the Gesell questionnaire. The language developmental quotient (LDQ) was determined using the following formula: language developmental age/present age $\times 100$. All of the assessments were conducted by a specifically assigned person. For the observer-blinded design of the study, the patients were randomly arranged before the tests, and the examiner was blinded to the names and the grouping of patients. The assessment results were recorded in the case reports.

The secondary measurement was patient survival and the incidence of the following adverse events: (1) fever, headache, allodynia, vomiting, infection, or other reactions; (2) clinical seizures and/or epileptic discharges on a serial electroencephalogram (EEG) at any time during hospitalization; (3) new lesions in the skull according to MRI at 6 months post-procedure; and (4) other clinically significant complications from the procedure during the long-term folow-up.

\section{Statistical analysis}

The data were expressed as the mean \pm S.E.M. The statistical significance of the patient ages, GMFM scores and language developmental quotients was detected using the one-way ANOVA analysis, LSD test and two-tailed Student's $t$-test. The statistical significance of gender and the GMFCS levels was detected using the chi-squared test. The statistical analysis was performed using SPSS 11.0.

\section{Results}

\section{Baseline characteristics of the patients}

A total of 30 patients with cerebral palsy in GMFCS levels III-V were enrolled in this study and were included in the transplantation group. The group consisted of 14 males and 16 females with a mean age of $5.53 \pm 1.20$ years (range, $1-32$ years). An additional 30 patients with cerebral palsy were treated with conventional methods and were included in the control group, which consisted of 14 males and 16 females with a mean age of $4.66 \pm 1.31$ years (range, $1-35$ years). The baseline characteristics of the patients in the two groups at the study onset are shown in Tables $1-2$. In addition, a comparison of the patient ages, LDQs and GMFM scores in the two groups are shown in Figure 3. No significant differences were found.

The MRI results from the skulls of patients with cerebral palsy can show a periventricular white matter injury (PWMI), and the pathological findings can include periventricular leukomalacia and diffused dysmyelination [23,24]. Prasad [25] studied 102 children 1-3 years of age with cerebral palsy and found that $47.1 \%$ had a PWMI in the skull based on MRI findings. In this study, 16 of the 30 patients $(54.5 \%)$ in the transplantation group had white matter injuries according to MRI.

\section{Functional outcomes of motor development among the two groups}

The motor functions of the patients were observed and evaluated using the GMFM scores before treatment and at 1,3 , and 6 months post-treatment (Table 1). The GMFM scores of all of the patients in the two groups gradually increased during the 6 months post-treatment, however, there were no significant differences in the control group. In contrast, the GMFM scores in the transplantation group at months 3 and 6 post-treatment were significantly higher compared with the baseline scores $(P=0.011$ and 0.001$)$, whereas there were no 
Table 1 Clinical characteristics of the $\mathbf{3 0}$ patients in the transplantation group

\begin{tabular}{|c|c|c|c|c|c|}
\hline No. & Gender & GMFCS stage & Age (years) & LDQ & GMFM \\
\hline 1 & Female & V & 1 & 72 & 36 \\
\hline 2 & Female & III & 3 & 31.7 & 176 \\
\hline 3 & Male & III & 4 & 28 & 189 \\
\hline 4 & Male & III & 4 & 92 & 185 \\
\hline 5 & Male & V & 3 & 100 & 50 \\
\hline 6 & Male & IV & 2 & 38 & 101 \\
\hline 7 & Male & V & 4.5 & 15 & 23 \\
\hline 8 & Male & IV & 4 & 26.8 & 115 \\
\hline 9 & Female & V & 3 & 75 & 42 \\
\hline 10 & Female & IV & 13 & 82 & 105 \\
\hline 11 & Female & V & 1.5 & 62 & 38 \\
\hline 12 & Male & V & 1 & 70 & 31 \\
\hline 13 & Female & V & 1 & 75 & 20 \\
\hline 14 & Male & IV & 2 & 90 & 63 \\
\hline 15 & Male & III & 4 & 98 & 191 \\
\hline 16 & Female & IV & 3 & 30 & 96 \\
\hline 17 & Male & IV & 21 & 80 & 82 \\
\hline 18 & Female & III & 2 & 98 & 120 \\
\hline 19 & Male & IV & 5 & 85 & 86 \\
\hline 20 & Female & III & 8 & 10 & 115 \\
\hline 21 & Female & III & 4 & 90 & 183 \\
\hline 22 & Female & V & 5 & 10 & 23 \\
\hline 23 & Female & III & 12 & 100 & 195 \\
\hline 24 & Male & IV & 2 & 98 & 83 \\
\hline 25 & Male & V & 1 & 15 & 12 \\
\hline 26 & Female & III & 6.5 & 90 & 193 \\
\hline 27 & Female & III & 4 & 92 & 196 \\
\hline 28 & Female & IV & 32 & 73 & 117 \\
\hline 29 & Female & V & 1 & 54 & 56 \\
\hline 30 & Male & III & 8.5 & 97 & 201 \\
\hline
\end{tabular}

The clinical characteristics of the 30 patients in the transplantation group before the cell transplantation treatment are shown. GMFCS: Gross Motor Function Classification System levels; LDQ: language developmental quotient; GMFM: Gross Motor Function Measurement scores.

significant changes in the GMFM scores at month 1 post-treatment $(P=0.265)$. The GMFM score increase from baseline to month 6 post-treatment was 58.6 (95\% CI: 25.8-91.4) in the transplantation group. This finding suggests that there was a significant recovery effect in motor function after the transplantation treatment. Additional movie files were shown in more detail (see Additional file 2 and 3). In addition, we found that the GMFM scores at months 3, and 6 post-treatment were significantly higher in the transplantation group compared with those in the control group ( $P=0.003$ and $P<0.001$, respectively). However, there were no differences in the GMFM scores at month
Table 2 Clinical characteristics of the $\mathbf{3 0}$ patients in the control group

\begin{tabular}{|c|c|c|c|c|c|}
\hline No. & Gender & GMFCS stage & Age (years) & LDQ & GMFM \\
\hline 1 & Female & V & 1 & 72 & 36 \\
\hline 2 & Female & III & 2.5 & 35 & 183 \\
\hline 3 & Male & III & 3.5 & 28 & 198 \\
\hline 4 & Male & III & 4 & 92 & 211 \\
\hline 5 & Male & V & 2 & 100 & 35 \\
\hline 6 & Male & V & 2 & 38 & 23 \\
\hline 7 & Male & V & 4.5 & 15 & 33 \\
\hline 8 & Male & IV & 3.5 & 27 & 110 \\
\hline 9 & Female & V & 2 & 75 & 51 \\
\hline 10 & Female & IV & 2.5 & 82 & 99 \\
\hline 11 & Male & IV & 1 & 60 & 80 \\
\hline 12 & Female & III & 15 & 95 & 201 \\
\hline 13 & Female & III & 1 & 62 & 135 \\
\hline 14 & Male & IV & 5 & 86 & 110 \\
\hline 15 & Female & IV & 2.5 & 95 & 98 \\
\hline 16 & Male & IV & 21 & 98 & 135 \\
\hline 17 & Male & IV & 35 & 82 & 90 \\
\hline 18 & Male & IV & 9 & 80 & 112 \\
\hline 19 & Female & V & 4 & 12 & 30 \\
\hline 20 & Female & V & 1 & 23 & 43 \\
\hline 21 & Male & V & 1.7 & 25 & 45 \\
\hline 22 & Female & V & 1 & 30 & 50 \\
\hline 23 & Female & III & 1.5 & 80 & 146 \\
\hline 24 & Female & V & 3 & 39 & 25 \\
\hline 25 & Male & IV & 2.5 & 96 & 99 \\
\hline 26 & Male & V & 2.6 & 100 & 28 \\
\hline 27 & Female & III & 2 & 86 & 100 \\
\hline 28 & Female & V & 1 & 65 & 45 \\
\hline 29 & Male & III & 1.5 & 85 & 125 \\
\hline 30 & Male & V & 1 & 64 & 43 \\
\hline
\end{tabular}

The clinical characteristics of the 30 patients in the control group are shown. GMFCS: Gross Motor Function Classification System levels; LDQ: language developmental quotient; GMFM: Gross Motor Function Measurement scores.

1 post-treatment between the two groups $(P=0.089)$ (Figure 4A). To evaluate the impact of NSC transplantation in patients with different levels of cerebral palsy, we divided the patients according to their GMFCS levels. The results indicated that patients in the transplantation group with levels IV and V had a better recovery of motor function (Figure 4B-D).

\section{Functional outcomes of language development among the two groups}

The language abilities of the patients were observed before treatment and at 1, 3, and 6 months post-treatment. The means of the language developmental quotients of 

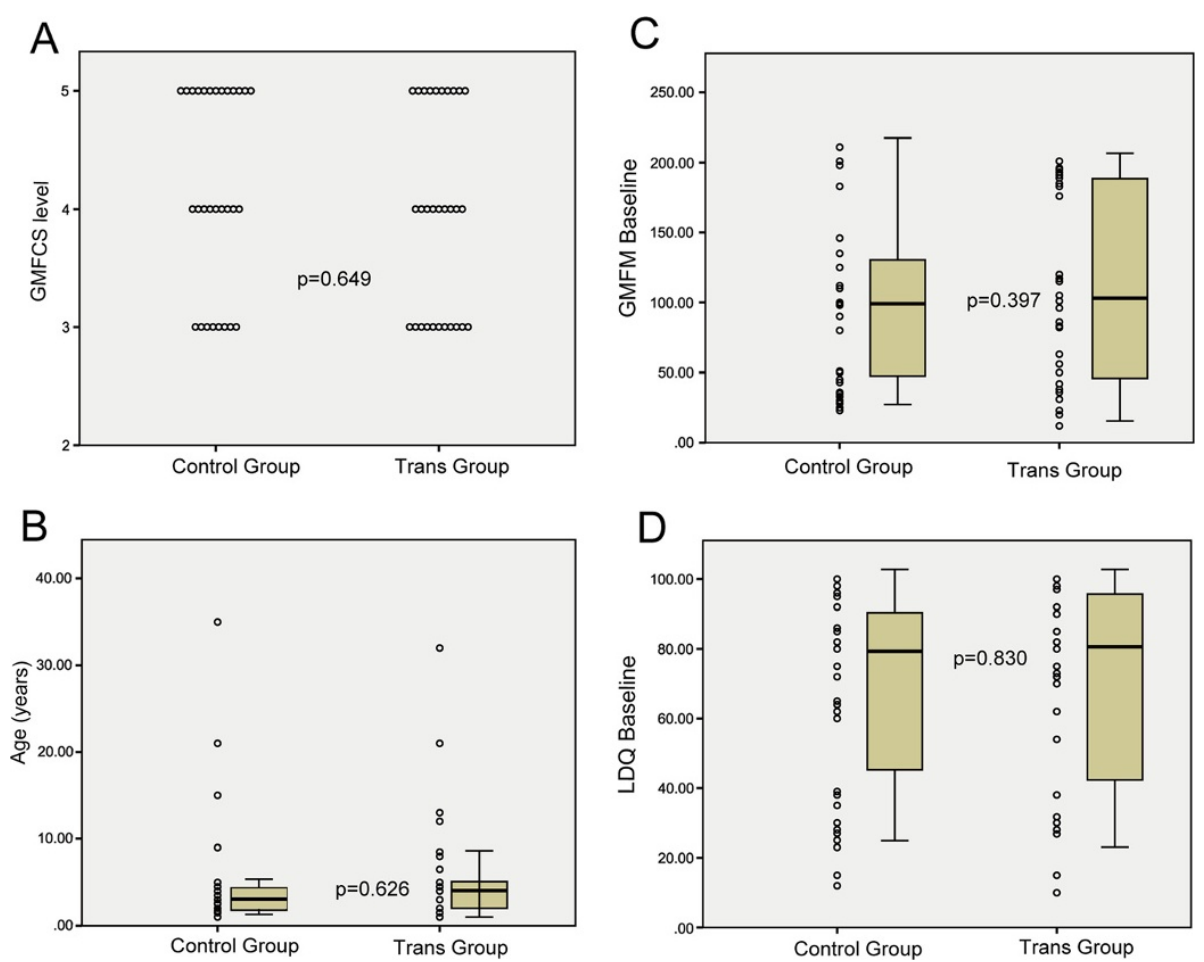

Figure 3 A comparison of the baseline characteristics of the patients in the two groups. (A) A comparison of the number of patients according to the Gross Motor Function Classification System (GMFCS) levels in the transplantation (Trans) and control groups. Statistically significant differences were detected using the chi-squared test. (B-D): A comparison of the mean ages (B), mean baseline Gross Motor Function Measure (GMFM) scores (C) and mean baseline language developmental quotients (LDQs) (D) of the patients in the transplantation (Trans) and control groups is shown. Statistically significant differences were detected between the groups using a Student $t$-test.

the patients in the two groups gradually increased during the 6 months post-treatment (Figure 5). However, no significant differences in the language developmental quotients were observed at months 1,3 , and 6 posttreatment when compared with the baseline quotients in both groups ( $\mathrm{P}>0.05$ for all). In addition, we did not find any significant differences in the language developmental quotients at months 1,3 , and 6 post-treatment between the two groups ( $P=0.751,0.522$ and 0.304 , respectively). This finding suggests that the recovery of language functions was not accelerated in the transplantation group.

\section{Adverse reactions in the transplantation group}

No new neurological deficits were immediately identified after NSC treatment. All of the patients in this study were observed for more than 6 months after treatment. None of the 60 patients experienced fever, headache, allodynia, vomiting, or other serious adverse events that were related to the experimental procedure. Follow-up MRI evaluations did not show any significant anatomical or structural changes that could indicate adverse events. There was no evidence of any new ischemic, haemorrhagic, or neoplastic lesions. However, an increase in the frequency of crying was reported in one patient but resolved spontaneously 2 days after the treatment without any intervention. Other possible adverse effects or complications in the control and transplantation groups were evaluated, but no differences were observed in the frequency of new-onset morbidities between the groups.

\section{Discussion}

Improvements in perinatal emergency medicine have decreased the neonatal mortality rate, however, the incidence of hypoxic ischemic encephalopathy and premature cerebral palsy have increased over time [1]. Conventional rehabilitation treatment for cerebral palsy cannot improve the motor function of patients with moderate-to-severe chronic cerebral palsy $[5,6]$. In this study, we did not find any significant improvement in the motor functions of the patients in the control group. However, in the transplantation group, our data indicated that the GMFM scores post-treatment were significantly higher after 3 months compared with the baselines scores, which suggests that the motor recovery effects were accelerated in the transplantation group. In addition, we found that patients in the transplantation group with GMFCS levels IV and V had a better recovery of motor functions. These results provide strong 

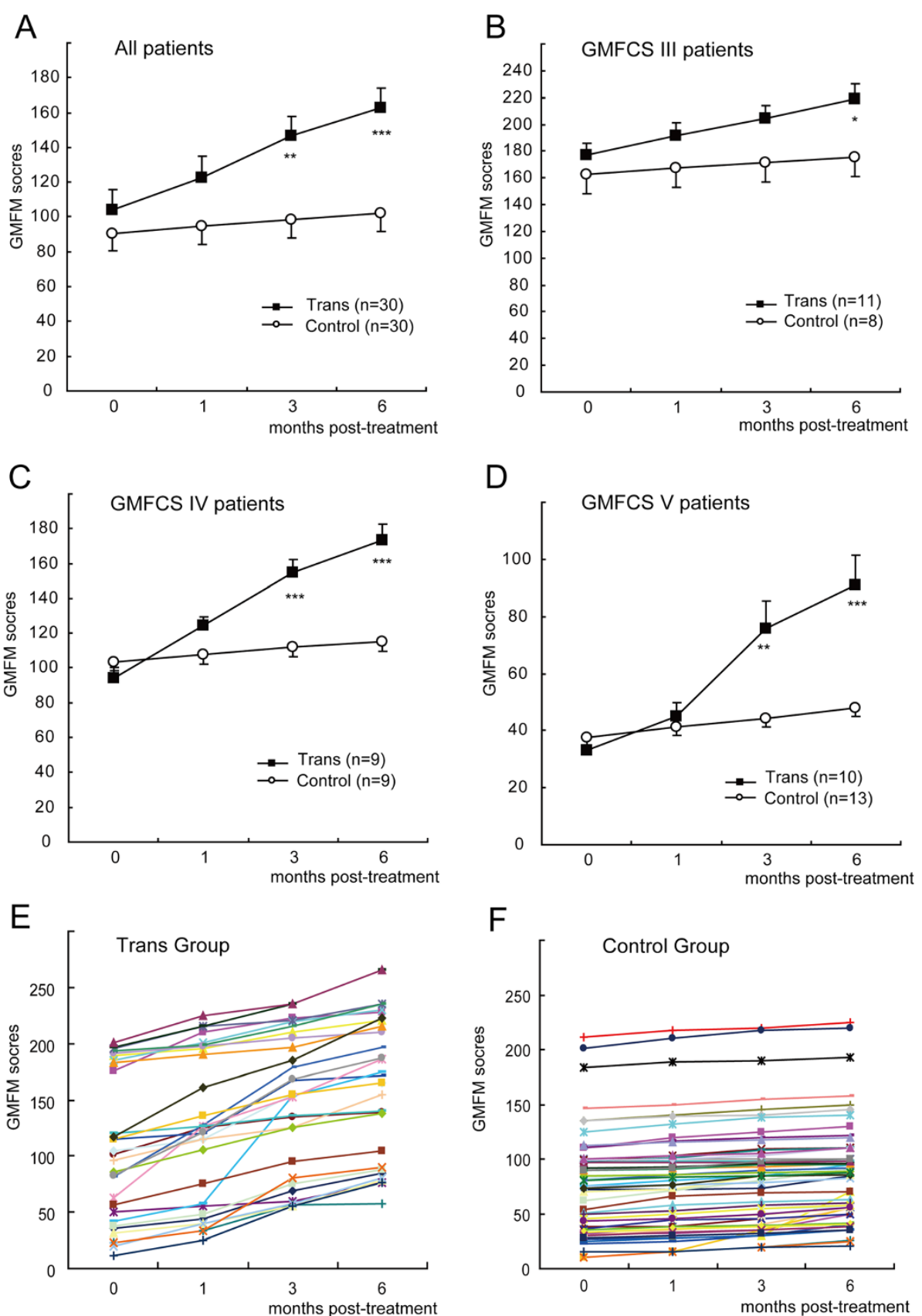

Figure 4 A comparison of the kinetic Gross Motor Function Measure (GMFM) scores of the patients in the two groups. (A) A

comparison of the mean GMFM scores before treatment ( 0 months) and at 1, 3, and 6 months post-treatment for the patients in the transplantation (Trans) and control groups. (B-D) A comparison of the mean GMFM scores for the patients with GMFCS levels III (B), IV(C) and V (D) in the transplantation (Trans) and control groups. The data were expressed as the mean \pm S.E.M. Statistically significant differences were detected between the groups using a two-tailed Student's $t$-test, ${ }^{*} P<0.05$, ${ }^{*} P<0.01$, ${ }^{* * *} P<0.001$. (E-F) Changes in the GMFM scores of the patients in the transplantation (Trans) group (E) and in the control group (F) before and after treatment. Each line indicates the kinetic scores of an individual patient.

clinical support for MSC-derived NSC-like cells transplantation for the treatment of cerebral palsy, especially for moderate-to-severe chronic cerebral palsy.

The mechanism by which NSCs contribute to motor function recovery remains controversial. Experiments have demonstrated that transplanted NSCs exhibit strong plasticity, can easily integrate with host cells and can establish a stable synaptic connection and become functional substituting nerve cells [26-28]. Additionally, NSCs may produce neurotrophic factors that facilitate 

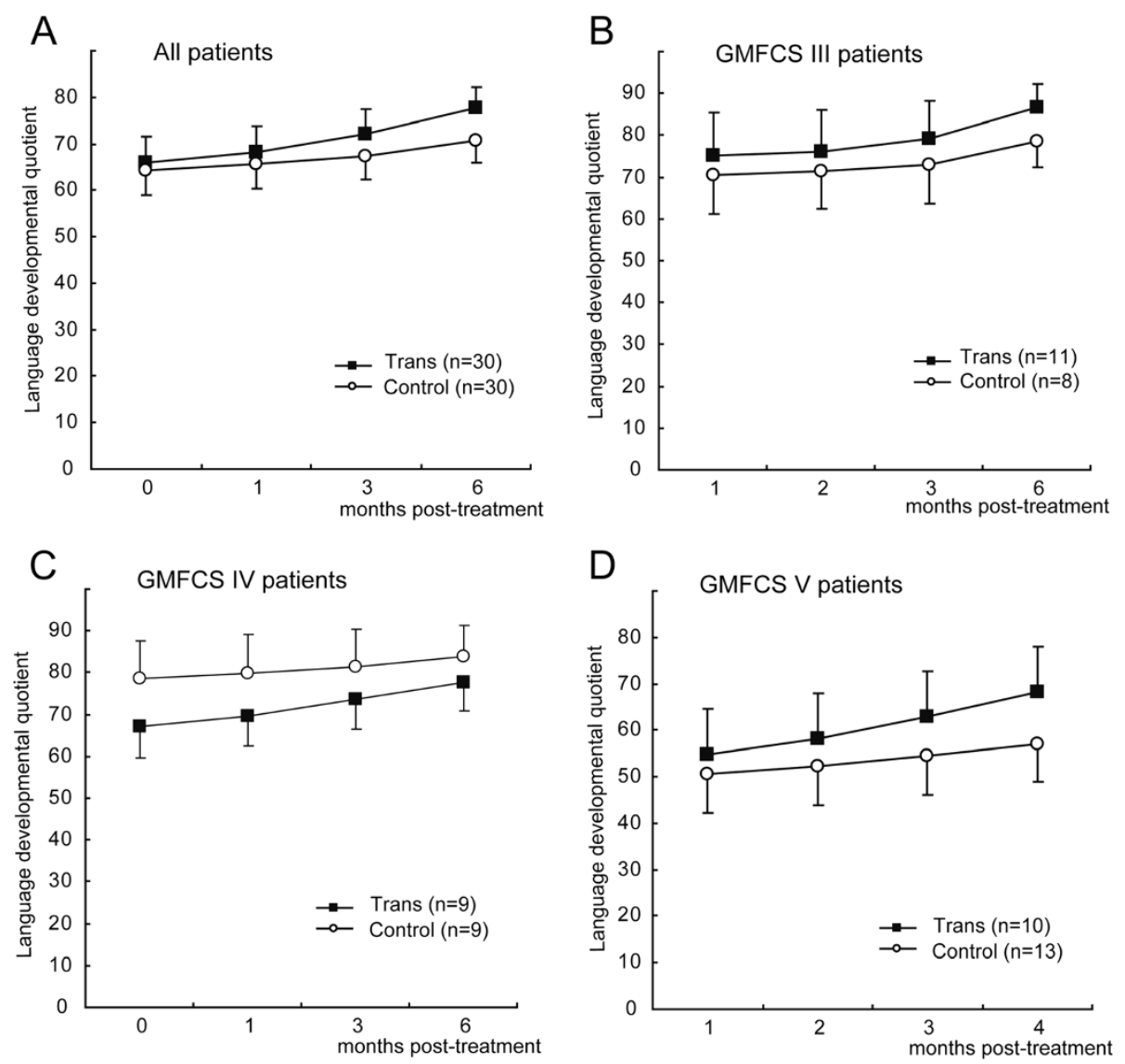

Figure 5 A comparison of the kinetic language developmental quotients of the patients in the two groups. (A) A comparison of the mean language developmental quotients before (0 months) and after treatment for the patients in the transplantation (Trans) and control groups. (B-D) A comparison of the mean language developmental quotients for the patients with GMFCS levels III (B), IV(C) and V (D) in the transplantation (Trans) and control groups. No statistically significant differences were detected between the groups using a two-tailed Student's t-test.

the recovery of impaired tissues in the diseased brain region [29-32]. Consistent with these findings, we found that autologous NSC-like cells derived from MSCs could differentiate into neuronal and glial lineages in vitro. Our study was not designed to address the mechanism of NSC functions in vivo, and future experiments are necessary to define the exact mechanism of therapeutic cerebral repair by NSCs.

The safety of the NSC-based cell therapy is another urgent problem. The risk for chromosomal aberrations, neoplastic transformation, increased telomerase activity, or both has been reported for human MSCs following several passages in culture in experimental settings [33]. We used early cultured MSCs (3-4 passage) that displayed normal karyotypes and telomerase activity to induce NSClike cells. Before each treatment, we confirmed the safety of induced NSC-like cells by telomerase activity evaluation, karyotype analysis and microbiological detection. To our knowledge, there are no clinical data that support the development of neoplasms that are directly related to an autologous MSC inoculum $[34,35]$. In this study, we evaluated the safety of MSCs and NSC-like cells in nude mice, and no tumour formation or other complications were found in a long-term (more than 3 months) study. Moreover, allodynia was reported to be a risk of intraspinal neural stem cell transplantation [30]. In this study, we did not find any cases of allodynia or other adverse events during the 6-month follow-up. Therefore, we confirmed that the cells in our study were safe for the patients, however, more long-term follow-up studies may be necessary to further confirm the safety of NSC-like cells.

In this study, we did not find any evidence of accelerated recovery of language function in the transplantation group. Language disorders in children with cerebral palsy are categorized as asophia, anarthria and language developmental delays [36], which are caused by a motor disturbance of the speech organs due to brain injury. Language recovery is affected by multiple factors [37]. The time period from 7-24 months after birth is important for establishing brain language signal pathways. In 
this study, all of the patients missed this key phase of language training. Therefore, stem cells combined with language training at an earlier stage may improve the language ability of these patients.

The main limitations of this study include the small sample size and the lack of a randomised, double-blinded, placebo-controlled design. However, we employed an observer-blinded, controlled design to minimize measurement bias. As shown in Figure 3, the baseline characteristics of the patients from the two groups are well matched, and no significant differences were found between the two groups in the comparison of the patient ages, LDQs and GMFM scores at the study onset. This study is the first reported controlled clinical trial of NSC-like cells therapy for chronic cerebral palsy, and our study provides strong clinical evidence that supports stem cell transplantation for the treatment of motor deficits related to cerebral palsy. Further randomised clinical trials are necessary to establish the efficacy of this procedure.

\section{Conclusion}

Our data indicates that the transplantation of MSC-derived NSC-like cells is safe and effective for the treatment of chronic cerebral palsy. Motor function, but not the language quotient, indicated optimal improvement 3 months after transplantation.

\section{Additional files}

\section{Additional file 1: Supplementary materials.}

Additional file 2: The motor ability of patient No. 4 in the transplantation group before and after treatment.

Additional file 3: The motor ability of patient No. 5 in the transplantation group before and after treatment.

\section{Competing interests}

The authors declare that they have no competing interests.

\section{Authors' contributions}

HQL conceived of the study, participated in its design, and drafted and revised the manuscript. GJC and YLW participated in the design of the study, collected and analysed the data, and drafted the manuscript. ZYX participated in the design of the study, analysed the data, drafted and revised the manuscript and performed the immunoassays. FF and RMX collected and analysed the data. YW drafted and revised the manuscript and performed the statistical analysis. XLH and LXF participated in the coordination of the study and helped draft the manuscript. All of the authors read and approved the final manuscript.

\section{Acknowledgement}

This study was supported by the National Key Basic Research and Development Project (Beijing, China) (No. 2011CB965101). We would also like to thank all of the patients whose participation made this study possible.

\section{Author details}

${ }^{1}$ Division of Pediatrics, Zhejiang General Hospital of Armed Police Forces, 16 South Lake Road, Jiaxing City 314000, China. ${ }^{2}$ Research Center of Developmental Biology, Second Military Medical University, 800 Xiangyin Road, Shanghai 200433, China.
Received: 23 September 2012 Accepted: 21 January 2013

Published: 26 January 2013

\section{References}

1. An T, Guo XQ, Pu XH: Study progress in early intervention of high- risk infants for the prevention and treatment of cerebral palsy. Clin Pediatr 2006, 24:696-698.

2. Moster D, Lie RT, Markestad T: Long-term medical and social consequences of preterm birth. N Engl J Med 2008, 359:262-273.

3. Hu YM: Jiang ZF. Zhu FT: Practice of pediatrics. People's medical publishing house; 2002.

4. Yeargin-Allsopp M, Van Naarden Braun K, Doernberg NS, Benedict RE, Kirby RS, Durkin MS: Prevalence of cerebral palsy in 8-year-old children in three areas of the United States in 2002: a multisite collaboration. Pediatrics 2008, 121:547-554.

5. Koman LA, Smith BP, Shilt JS: Cerebral palsy. Lancet 2004, 363:1619-1631.

6. Holt RL, Mikati MA: Care for child development: basic science rationale and effects of interventions. Pediatr Neurol 2011, 44:239-253.

7. Luan Z, Yin GC, Hu XH, Qu SQ, Wu NH, Yan FQ, Qian YM, Jin HY, Gong XJ: [Treatment of an infant with severe neonatal hypoxic-ischemic encephalopathy sequelae with transplantation of human neural stem cells into cerebral ventricle]. Zhonghua Er Ke Za Zhi 2005, 43:580-583. discussion 580

8. Chen GJ, Fang F, Tang YH: Cell Therapy of cerebral diseases in China: a meta-analysis. Med J Chin PAPF 2011, 22:216-218.

9. Carroll JE, Mays RW: Update on stem cell therapy for cerebral palsy. Expert Opin Biol Ther 2011, 11:463-471.

10. Trounson A, Thakar RG, Lomax G, Gibbons D: Clinical trials for stem cell therapies. BMC Med 2011, 9:52.

11. Du K, Luan Z, Qu SQ: Clinical outcome of bone marrow mesenchymal stem cells transplantation in children with severe cerebral palsy. Clin Pediatr 2011, 29:55-58

12. Wang XD, Yang J, Li M: Effects of bone marrow mesenchymal stem cell graft on gross motor function in children with cerebral. Journal of China-Japan Friendship Hospital 2010, 24:337-342.

13. Bartley J, Carroll JE: Stem cell therapy for cerebral palsy. Expert Opin Biol Ther 2003, 3:541-549.

14. Long X, Olszewski M, Huang W, Kletzel M: Neural cell differentiation in vitro from adult human bone marrow mesenchymal stem cells. Stem Cells Dev 2005, 14:65-69.

15. Hermann A, Gastl R, Liebau S, Popa MO, Fiedler J, Boehm BO, Maisel M, Lerche $H$, Schwarz J, Brenner R, Storch A: Efficient generation of neural stem cell-like cells from adult human bone marrow stromal cells. J Cell Sci 2004, 117:4411-4422.

16. Deng J, Petersen BE, Steindler DA, Jorgensen ML, Laywell ED: Mesenchymal stem cells spontaneously express neural proteins in culture and are neurogenic after transplantation. Stem Cells 2006, 24:1054-1064.

17. Zhao ZM, Li HJ, Liu HY, Lu SH, Yang RC, Zhang QJ, Han ZC: Intraspinal transplantation of CD34+ human umbilical cord blood cells after spinal cord hemisection injury improves functional recovery in adult rats. Cell Transplant 2004, 13:113-122.

18. Enzmann GU, Benton RL, Talbott JF, Cao Q, Whittemore SR: Functional considerations of stem cell transplantation therapy for spinal cord repair. J Neurotrauma 2006, 23:479-495.

19. Mazzini L, Mareschi K, Ferrero I, Vassallo E, Oliveri G, Nasuelli N, Oggioni GD, Testa L, Fagioli F: Stem cell treatment in Amyotrophic Lateral Sclerosis. J Neurol Sci 2008, 265:78-83.

20. Mazzini L, Ferrero I, Luparello V, Rustichelli D, Gunetti M, Mareschi K, Testa L, Stecco A, Tarletti R, Miglioretti M, et al: Mesenchymal stem cell transplantation in amyotrophic lateral sclerosis: A Phase I clinical trial. Exp Neurol 2010, 223:229-237.

21. Dominici M, Le Blanc K, Mueller I, Slaper-Cortenbach I, Marini F, Krause D, Deans R, Keating A, Prockop D, Horwitz E: Minimal criteria for defining multipotent mesenchymal stromal cells. The International Society for Cellular Therapy position statement. Cytotherapy 2006, 8:315-317.

22. Lundkvist Josenby A, Jarnlo GB, Gummesson C, Nordmark E: Longitudinal construct validity of the GMFM- 88 total score and goal total score and the GMFM-66 score in a 5-year follow-up study. Phys Ther 2009, 89:342-350 
23. Back SA, Craig A, Luo NL, Ren J, Akundi RS, Ribeiro I, Rivkees SA: Protective effects of caffeine on chronic hypoxia-induced perinatal white matter injury. Ann Neurol 2006, 60:696-705.

24. Back SA, Craig A, Kayton RJ, Luo NL, Meshul CK, Allcock N, Fern R: Hypoxiaischemia preferentially triggers glutamate depletion from oligodendroglia and axons in perinatal cerebral white matter. J Cereb Blood Flow Metab 2007, 27:334-347.

25. Prasad R, Verma N, Srivastava A, Das BK, Mishra OP: Magnetic resonance imaging, risk factors and co-morbidities in children with cerebral palsy. J Neurol 2011, 258:471-478.

26. Park Kl, Himes BT, Stieg PE, Tessler A, Fischer I, Snyder EY: Neural stem cells may be uniquely suited for combined gene therapy and cell replacement: Evidence from engraftment of Neurotrophin-3-expressing stem cells in hypoxic-ischemic brain injury. Exp Neurol 2006, 199:179-190.

27. Chamberlain G, Fox J, Ashton B, Middleton J: Concise review: mesenchymal stem cells: their phenotype, differentiation capacity, immunological features, and potential for homing. Stem Cells 2007, 25:2739-2749.

28. Iwanami A, Kaneko S, Nakamura M, Kanemura Y, Mori H, Kobayashi S, Yamasaki M, Momoshima S, Ishii H, Ando K, et al: Transplantation of human neural stem cells for spinal cord injury in primates. J Neurosci Res 2005, 80:182-190.

29. $\mathrm{Ma} \mathrm{H}, \mathrm{Yu} B$, Kong L, Zhang $Y$, Shi $Y$ : Neural stem cells over-expressing brain-derived neurotrophic factor (BDNF) stimulate synaptic protein expression and promote functional recovery following transplantation in rat model of traumatic brain injury. Neurochem Res 2012, 37:69-83.

30. Hofstetter CP, Holmstrom NA, Lilja JA, Schweinhardt P, Hao J, Spenger C, Wiesenfeld-Hallin Z, Kurpad SN, Frisen J, Olson L: Allodynia limits the usefulness of intraspinal neural stem cell grafts; directed differentiation improves outcome. Nat Neurosci 2005, 8:346-353.

31. Lim JY, Park SI, Kim SM, Jun JA, Oh JH, Ryu CH, Jeong CH, Park SH, Park SA Oh W, et al: Neural Differentiation of Brain-derived Neurotrophic Factorexpressing Human Umbilical Cord Blood-derived Mesenchymal Stem Cells in Culture via TrkB-mediated ERK and beta-catenin Phosphorylation and following Transplantation into the Developing Brain. Cell Transplant 2011, 20:1855-1866.

32. Chekhonin VP, Lebedev SV, Volkov Al, Pavlov KA, Ter-Arutyunyants AA Volgina NE, Savchenko EA, Grinenko NF, Lazarenko IP: Activation of expression of brain-derived neurotrophic factor at the site of implantation of allogenic and xenogenic neural stem (progenitor) cells in rats with ischemic cortical stroke. Bull Exp Biol Med 2011, 150:515-518.

33. Momin EN, Mohyeldin A, Zaidi HA, Vela G, Quinones-Hinojosa A: Mesenchymal stem cells: new approaches for the treatment of neurological diseases. Curr Stem Cell Res Ther 2010, 5:326-344.

34. Centeno CJ, Schultz JR, Cheever M, Freeman M, Faulkner S, Robinson B, Hanson R: Safety and complications reporting update on the reimplantation of culture-expanded mesenchymal stem cells using autologous platelet lysate technique. Curr Stem Cell Res Ther 2011, 6:368-378.

35. Tan J, Wu W, Xu X, Liao L, Zheng F, Messinger S, Sun X, Chen J, Yang S, Ca J, et al: Induction therapy with autologous mesenchymal stem cells in living-related kidney transplants: a randomized controlled trial. JAMA 2012, 307:1169-1177.

36. Parkes J, Hill N, Platt MJ, Donnelly C: Oromotor dysfunction and communication impairments in children with cerebral palsy: a register study. Dev Med Child Neurol 2010, 52:1113-1119.

37. Pennington L, Miller N, Robson S, Steen N: Intensive speech and language therapy for older children with cerebral palsy: a systems approach. Dev Med Child Neurol 2010, 52:337-344.

doi:10.1186/1479-5876-11-21

Cite this article as: Chen et al: Neural stem cell-like cells derived from autologous bone mesenchymal stem cells for the treatment of patients with cerebral palsy. Journal of Translational Medicine 2013 11:21.

\section{Submit your next manuscript to BioMed Central and take full advantage of:}

- Convenient online submission

- Thorough peer review

- No space constraints or color figure charges

- Immediate publication on acceptance

- Inclusion in PubMed, CAS, Scopus and Google Scholar

- Research which is freely available for redistribution

Submit your manuscript at www.biomedcentral.com/submit
C Biomed Central 